
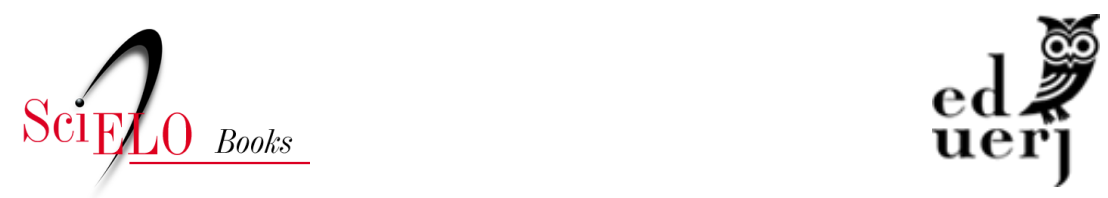

\title{
Capítulo 4 - Conflito partidário no Senado Federal
}

\author{
Júlio Canello \\ Debora Gershon \\ Leonardo Martins Barbosa
}

\section{SciELO Books / SciELO Livros / SciELO Libros}

CANELLO, J., GERSHON, D., and BARBOSA, L. M. Conflito partidário no Senado Federal. In.: SANTOS, F., ed. Congresso remoto: a experiência legislativa brasileira em tempos de pandemia [online]. Rio de Janeiro, 2021, pp. 65-80. Sociedade e política collection. ISBN: 978-65-88808-12-2.

https://doi.org/10.7476/9786588808122.0006.

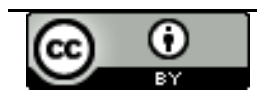

All the contents of this work, except where otherwise noted, is licensed under a Creative Commons Attribution 4.0 International license.

Todo o conteúdo deste trabalho, exceto quando houver ressalva, é publicado sob a licença Creative Commons Atribição 4.0.

Todo el contenido de esta obra, excepto donde se indique lo contrario, está bajo licencia de la licencia Creative Commons Reconocimento 4.0. 


\section{Capítulo 4 \\ Conflito partidário no Senado Federal}

Júlio Canello

Debora Gershon

Leonardo Martins Barbosa

\section{Apresentação}

Este capítulo analisa o comportamento do Senado Federal em tempos de pandemia. O Sistema de Deliberação Remota (SDR) mudou a dinâmica de funcionamento da Casa, com impacto sobre temas abordados, regras do processo decisório e organização das forças partidárias nas casas legislativas, especialmente no Senado, que já retomou parte de suas atividades em regime híbrido (remoto e presencial).

Desde o início da legislatura até o fim de agosto de 2020, o Senado Federal decidiu sobre 650 matérias, entre medidas provisórias, projetos de lei, projetos de lei complementar, propostas de emenda à Constituição, além de substitutivos e emendas da Câmara dos Deputados. Para avaliar a dinâmica política e a agenda do Senado na pandemia, comparamos seu comportamento neste período de funcionamento excepcional com o período pré-pandemia. Analisamos os seguintes aspectos da produção legislativa: tema e destino das matérias decididas, grau de consenso em plenário e apoio ao governo em votações nominais, sempre em comparação 
com a experiência legislativa anterior. O resultado é a figura de um parlamento que priorizou o debate sobre a crise de Covid-19, em coordenação com a Câmara, mas que reduziu sua aderência às propostas e posições governamentais.

\section{Os temas do Senado no período remoto}

Das 650 proposições sobre as quais o Senado se debruçou de 2019 para cá, 186 (28\%) foram apresentadas durante a pandemia de Covid-19, enquanto outras 464 foram iniciadas antes de março. Destas, no entanto, 47 foram decididas já pelo SDR.

Se analisados esses projetos de acordo com a classificação temática proposta pelo próprio Senado, nota-se que, na atual legislatura, o debate esteve centrado em projetos de natureza social, antes e durante a pandemia, com leve variação positiva depois de março, o que representa atenção específica a proposições de impacto possivelmente mais direto sobre a vida da população em período de crise.

Proposições de natureza econômica também se destacam de forma geral, embora particularmente mais durante o período de Covid-19, possivelmente pelas mesmas razões. É indício, portanto, de que as restrições previstas no SDR para votação prioritária de projetos relacionados à situação de emergência pública foram majoritariamente observadas pelo Senado, tanto quanto o foram pela Câmara, a despeito do fato de ter havido, no Senado, maior centralidade do presidente da Casa na condução dos trabalhos, em detrimento de espaços colegiados. 
Tabela 8. Projetos decididos no Senado, por tema geral

\begin{tabular}{lcc}
\hline Destinação & Pandemia & Pré-Pandemia \\
\hline Administrativo & $14(6 \%)$ & $40(9 \%)$ \\
\hline Social & $86(38 \%)$ & $145(34 \%)$ \\
\hline Econômico & $66(29 \%)$ & $80(19 \%)$ \\
\hline Honorífico & $1(<1 \%)$ & $51(12 \%)$ \\
\hline Jurídico & $41(18 \%)$ & $100(24 \%)$ \\
\hline Orçamentário & $16(7 \%)$ & $4(1 \%)$ \\
\hline Não identificado & $4(2 \%)$ & $2(<1 \%)$ \\
\hline Total & $228(100 \%)$ & 422 \\
\hline
\end{tabular}

Fonte: Observatório do Legislativo Brasileiro (OLB).

Analisados por subtemas, e desconsiderados aqueles de menor frequência, observamos que, assim como na Câmara, o tópico de maior interesse dos(as) senadores(as) foi a saúde, seguido por política econômica e assistência social. Isso indica que houve mudança explícita no foco da atenção dos parlamentares como resposta à crise sanitária. Os principais subtemas tratados anteriormente eram homenagem cívica, família e proteção a crianças, adolescentes e mulheres, além de direito civil e processual civil.

Tabela 9. Projetos decididos no Senado, por tema específico

\begin{tabular}{lcc}
\hline Destinação & Pandemia & Pré-Pandemia \\
\hline Saúde & 26 & 19 \\
\hline $\begin{array}{l}\text { Política econômica e sistema } \\
\text { financeiro }\end{array}$ & 23 & 6 \\
\hline Assistência social & 19 & 4 \\
\hline Crédito extraordinário & 16 & 4 \\
\hline Defesa do consumidor & 12 & 13 \\
\hline Tributação & 11 & 15 \\
\hline Direito civil e processual civil & 11 & 29 \\
\hline Educação & 9 & 19
\end{tabular}




\begin{tabular}{lcc}
\hline Destinação & Pandemia & Pré-Pandemia \\
\hline Trânsito & 8 & 11 \\
\hline Trabalho e emprego & 6 & 13 \\
\hline $\begin{array}{l}\text { Família, proteção a crianças, adoles- } \\
\text { centes, mulheres e idosos }\end{array}$ & 6 & 29 \\
\hline $\begin{array}{l}\text { Administração pública: órgãos } \\
\text { públicos }\end{array}$ & 5 & 17 \\
\hline Direitos humanos e minorias & 4 & 15 \\
\hline $\begin{array}{l}\text { Organização político-administrati- } \\
\text { va do Estado }\end{array}$ & 3 & 11 \\
\hline Direito penal e processual penal & 3 & 21 \\
\hline Minas e energia & 2 & 10 \\
\hline Meio ambiente & 2 & 19 \\
\hline Desenvolvimento regional & 2 & 10 \\
\hline Previdência social & 1 & 14 \\
\hline Data comemorativa & 1 & 13 \\
\hline Homenagem cívica & 0 & 38 \\
\hline $\begin{array}{l}\text { Outros (menos de } 10 \text { por tema em } \\
\text { cada período) }\end{array}$ & 58 & 92 \\
\hline Fonte Obsevato & & \\
\hline
\end{tabular}

Fonte: Observatório do Legislativo Brasileiro (OLB).

Quanto ao processo legislativo, há uma diferença significativa entre os dois períodos analisados, sobretudo pela suspensão das comissões. Enquanto 130 matérias foram aprovadas por essas instâncias colegiadas até março, apenas onze o foram depois desse mês, e, mesmo assim, antes da vigência do SDR. Esse é um dos elementos que denotam o prejuízo relativo causado pelo processo de deliberação remota à qualidade das deliberações, na medida em que as comissões são espaços privilegiados de debate e participação, que contribuem para uma tomada de decisão mais bem informada por parte do parlamentar. A proporção de matérias aprovadas no período (41\%) é, no entanto, praticamente idêntica ao período pré-pandemia (42\%), cabendo ressaltar que os dois 
intervalos de tempo não são comparáveis em termos absolutos, uma vez que não têm o mesmo número de meses.

É importante também chamar a atenção para o crescimento de proposições que foram prejudicadas (ou seja, com tramitação inviabilizada) ou que perderam eficácia (MPV com prazo esgotado). No primeiro caso, as próprias regras impostas pelo SDR, formalizadas em ato da Comissão Diretora (ATC 07/2020), são justificativas plausíveis. No segundo, as desavenças entre o Senado e o Planalto a respeito de como reagir à pandemia são uma hipótese explicativa potente.

Tabela 10. Projetos decididos no Senado, por decisão

\begin{tabular}{lcc}
\hline Destinação & Pandemia & Pré-Pandemia \\
\hline Aprovada pelo Plenário & $93(41 \%)$ & $176(42 \%)$ \\
\hline Aprovada por Comissão & $11(5 \%)$ & $130(31 \%)$ \\
\hline Rejeitada pelo Plenário & $1(<1 \%)$ & $3(1 \%)$ \\
\hline Rejeitada por Comissão & $5(2 \%)$ & $19(5 \%)$ \\
\hline Perda de Eficácia & $32(14 \%)$ & $24(6 \%)$ \\
\hline Prejudicada & $52(23 \%)$ & $7(2 \%)$ \\
\hline Retirada & $33(14 \%)$ & $62(15 \%)$ \\
\hline $\begin{array}{l}\text { Revogada/Transformada } \\
\text { em Indicação }\end{array}$ & $1(<1 \%)$ & $1(<1 \%)$ \\
\hline Total & $228(100 \%)$ & 422 \\
\hline
\end{tabular}

Fonte: Observatório do Legislativo Brasileiro (OLB).

Do ponto de vista do destino das proposições, variável relevante para avaliação do caráter eventualmente terminativo da tramitação de um projeto no Senado, cabem algumas observações. Em comparação com o período pré-pandemia, a partir de março de 2020 houve maior proporção de proposições arquivadas, menor volume de projetos remetidos à Câmara e proporção semelhante de projetos encaminhados à sanção/promulgação. Mais uma vez, 
os dados falam a favor da tramitação de uma agenda estritamente urgente e com maior grau de acordo entre as casas legislativas, tendo em vista que uma proposição que não retorna à Câmara não foi modificada pelo Senado.

Tabela 11. Projetos decididos no Senado, por destinação

\begin{tabular}{lcc}
\hline Destinação & Pandemia & Pré-Pandemia \\
\hline Sanção/Promulgação & $54(24 \%)$ & $111(26 \%)$ \\
\hline Câmara & $50(22 \%)$ & $195(46 \%)$ \\
\hline Arquivamento & $124(55 \%)$ & $116(27 \%)$ \\
\hline Total & $228(100 \%)$ & $422(100 \%)$ \\
\hline
\end{tabular}

Fonte: Observatório do Legislativo Brasileiro (OLB).

\section{Consenso e conflito entre parlamentares: o que mudou na pandemia}

Para além de um panorama mais agregado dos projetos decididos na atual legislatura, a análise das votações nominais no plenário do Senado revela facetas importantes do comportamento de parlamentares e partidos no período. Um primeiro aspecto geral dessa dinâmica é o número total de votações realizadas nominalmente. Para compararmos o desempenho desse governo com anteriores, consideramos apenas as votações realizadas até o fim do mês de agosto do segundo ano de cada mandato presidencial (excluído o de Michel Temer, por ter se iniciado já no fim do segundo ano). 
Tabela 12. Votações nominais no plenário do Senado, por governo

\begin{tabular}{lc}
\hline Governo & Número de votações \\
\hline Bolsonaro & 153 \\
\hline Dilma II & 109 \\
\hline Dilma I & 83 \\
\hline Lula II & 64 \\
\hline Lula I & 118 \\
\hline Fonte: Observatório do Legislativo Brasileiro (OLB).
\end{tabular}

Diferentemente das informações ofertadas pela Câmara dos Deputados, não há, para o Senado, registro sistematizado e amplamente acessível das votações simbólicas, ou seja, daquelas em que não há manifestação individual de posicionamento ou participação do parlamentar. A informação seria importante, pois enquanto as votações nominais são reservadas a temas que geram maior polêmica, a votação simbólica é indicativa de maior grau de consenso na matéria. Vale sublinhar que o número de votaçôes nominais sob o governo de Bolsonaro é o maior entre os períodos examinados.

Com base nas votaçôes nominais, calculamos uma medida para avaliar o consenso em plenário no período inicial de cada um dos governos analisados. $\mathrm{O}$ indicador representa a diferença absoluta entre votos sim e votos não (e outros) sobre o total de votos. Quanto mais próximo de 1 , maior é o consenso em torno da posição majoritária. Quanto mais próximo de 0 , maior é a divisão no plenário. A figura 4 mostra um resumo dos dados. Os pontos coloridos ao longo das retas representam o grau de consenso nas votações, bem como indicam a dispersão desses valores, ou seja, se estão concentrados ou não. Quanto maior for o ponto, mais vezes um determinado valor esteve presente nos dados. Os círculos de cor preta mostram as médias dessa variável em cada governo. É importante notar que quanto mais à esquerda está o círculo, menor é o grau de consenso em votações nominais no período analisado, e vice-versa. 
Figura 4. Grau de consenso em votações nominais no plenário do Senado, por governo

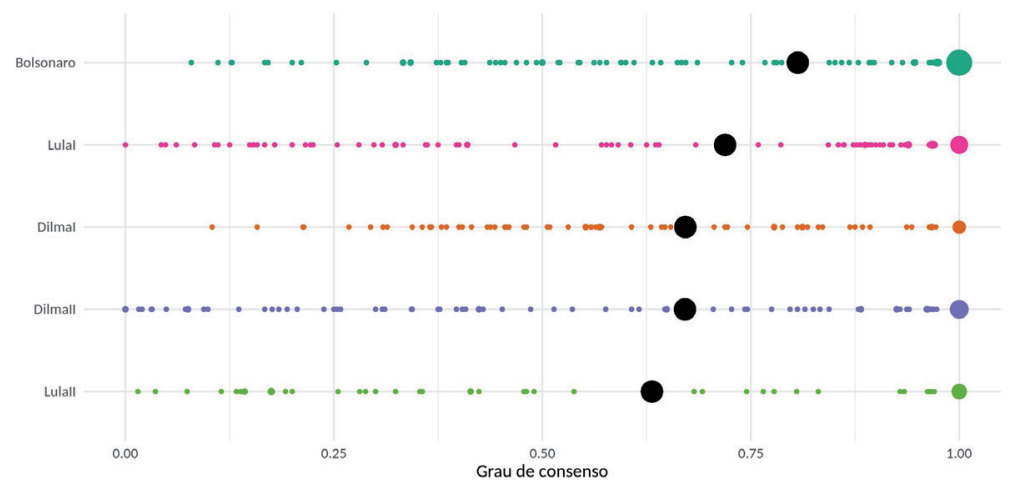

Fonte: Observatório do Legislativo Brasileiro (OLB).

O governo Bolsonaro teve o maior grau médio de consenso em votações no Senado se comparado aos governos de Dilma e de Lula. Entretanto, de maneira distinta do que se observa na Câmara, há uma grande proporção de casos unânimes em todos os governos, ainda que, mesmo assim, o atual se destaque (o que se revela pelo tamanho dos pontos na extremidade direita do gráfico). Ou seja, o Senado tende a ter um comportamento mais consensual, mas o teve de forma especialmente alta no presente governo.

Se comparadas as votações antes e durante a pandemia na legislatura atual, não há diferença expressiva quanto ao grau médio de consenso alcançado em plenário. Houve um pequeno aumento dessa medida de $80,2 \%$ para $80,9 \%$ após a adoção do SDR, além de crescimento do quórum médio de senadores votantes (de 65 para 74), o que reforça o cenário de diminuição do conflito na Casa. Esse padrão, no entanto, é distinto do observado na Câmara, já que lá a crise de Covid-19 resultou em aumento do dissenso. 
Figura 5. Grau de consenso em votações nominais no plenário do Senado

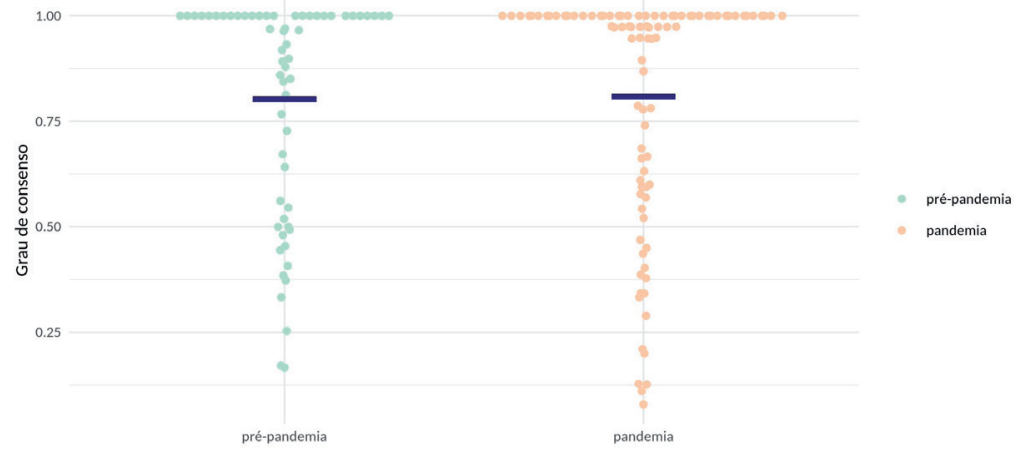

Fonte: Observatório do Legislativo Brasileiro (OLB).

Mesmo com alto grau de consenso, há diferenças significativas entre o comportamento dos Senadores. Medimos a distância entre o posicionamento dos parlamentares nas matérias que contaram com algum grau de dissenso. Com isso, é possível olhar com maior precisão o padrão de conflito no Senado. Em geral, no Brasil esse conflito ocorre entre uma maioria governista e uma minoria oposicionista. Contudo, nem sempre esse é o caso. Nesta seção, medimos o distanciamento do posicionamento dos parlamentares entre si. Na próxima, avaliamos de maneira mais específica se as mudanças no conflito parlamentar durante a pandemia podem ou não ser associadas a mudanças na relação entre Senado e governo.

Para medir o posicionamento e alinhamento dos senadores nas votações, utilizamos um algoritmo consolidado na ciência política, o WNominate. Em primeiro lugar, descartamos as votações unânimes e, em seguida, o algoritmo diferencia votos e votações por ordem de importância e retorna um ranking que nos permite posicionar os parlamentares. Neste capítulo, utilizamos uma escala que varia de 0 a 10 . Quanto mais próximos de polos opostos, mais dois parlamentares apresentam posicionamentos contrários entre si. Os resultados obtidos 
com esse algoritmo e escala posicionaram os senadores da oposição em valores mais próximos de 0 , assim como aqueles que compõem a base do governo com valores mais próximos de 10 .

Na figura 6, nota-se que durante a pandemia há uma redução dos Senadores situados entre as posições 9 e 10 (mais próximo ao governo) e, de maneira concomitante, verifica-se um aumento da frequência no intervalo entre 3 e 6 (mais próximo à oposição). Em termos agregados, o percentual de senadores com posicionamento acima de 7 caiu de 61\%, antes da pandemia, para 38\%, após a crise. Em outras palavras, o que podemos observar é que se desfez um quadro de maioria parlamentar (entre 7 e 10) que se impunha sobre uma minoria (entre 0 e 3 ), e houve uma aproximação geral entre os parlamentares, em torno de posições médias (de 4 a 6). Ou seja, na pandemia, o comportamento dos senadores que antes compunham um bloco majoritário mais propenso a negociar com o governo se desfez, dando lugar a um comportamento mais próximo da oposição.

Figura 6. Alinhamento em votações no Senado Número de senadores por posição

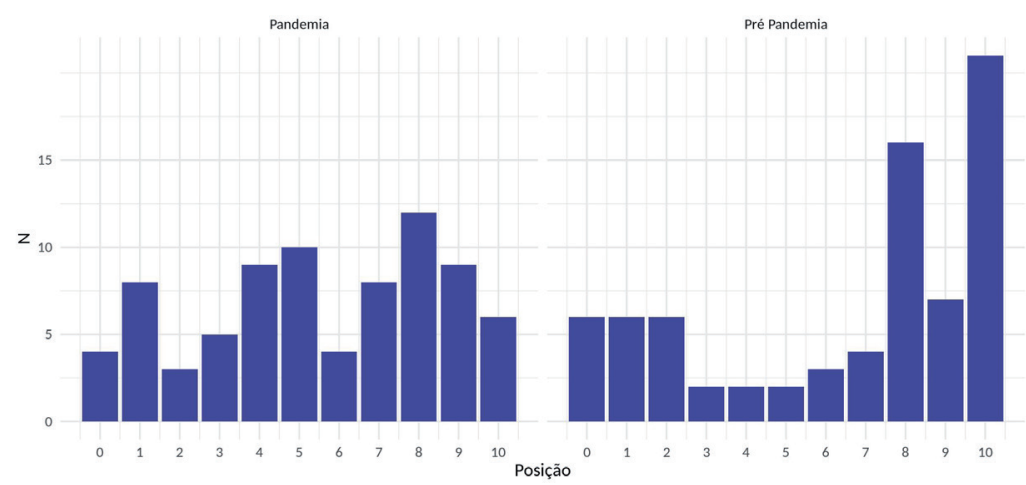

Fonte: Observatório do Legislativo Brasileiro (OLB). 
Em termos partidários, a figura 7 mostra o alinhamento do Senado, pré-pandemia e pandemia. Os pontos representam as posições estimadas para cada senador(a). As faixas denotam a distribuição de cada bancada, ordenada conforme a média do partido. A linha tracejada indica a mediana da maioria no plenário, por volta da nota 8.

Figura 7. Alinhamento em votações no Senado, por partido

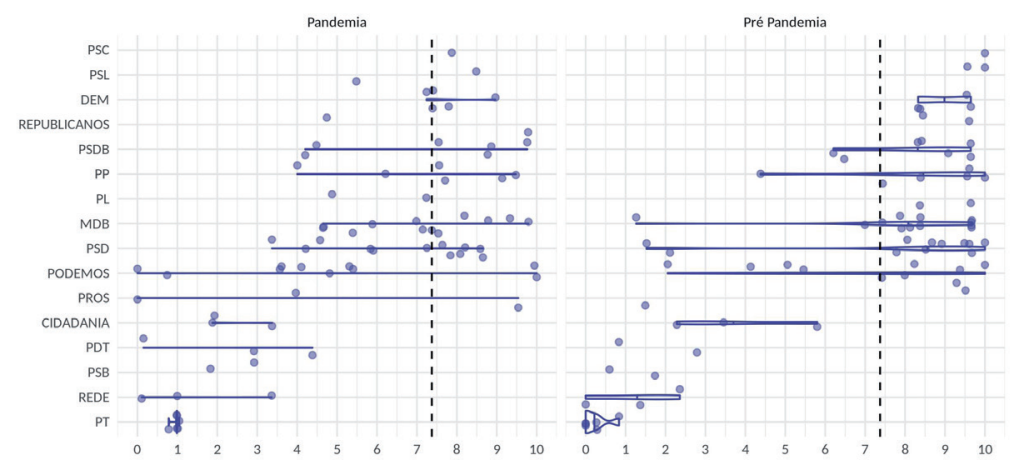

Fonte: Observatório do Legislativo Brasileiro (OLB).

Obs.: Pontos são posições de cada parlamentar. Tracejado é a mediana.

No período pré-pandemia, o Partido Social Cristão (PSC), o PSL, o Democratas (DEM) e o Republicanos destacam-se como agremiações com posições à direita da mediana do plenário, enquanto o Partido dos Trabalhadores (PT), a Rede, o Partido Socialista Brasileiro (PSB) e o Partido Democrático Trabalhista (PDT) destacam-se no extremo oposto. Com a crise de Covid-19, não há grandes mudanças nesse cenário. A mediana segue praticamente no mesmo ponto, com pequena redução na quantidade de parlamentares com nota inferior a 7 . O alinhamento dos partidos também segue na mesma direção, com poucas mudanças na dispersão intrapartidária e aumento da dispersão em partidos de diferentes matizes ideológicas, como Rede, PDT e PROS. 
Ou seja, embora o padrão de conflito tenha permanecido o mesmo na Casa, notamos maior dispersão em alguns partidos, e pequenos deslocamentos em outros, o que pode representar uma diminuição marginal na disciplina ou coesão dos partidos. Isso pode ter contribuído para o quadro geral de distensionamento entre os parlamentares durante a pandemia, conforme se mostrou na figura 5 . Acreditamos que as razões para isso estão na postura mais crítica adotada pelo bloco majoritário do Senado em relação ao governo, e a consequente aproximação dos parlamentares minoritários ao posicionamento médio da Casa.

\section{Posicionamento crítico e redução do apoio ao governo}

Com o objetivo de melhor entender a aproximação entre parlamentares nas matérias polêmicas e, ao mesmo tempo, avaliar a qualidade da relação entre os poderes durante a pandemia, também observamos se houve mudanças na taxa média de apoio ao governo na Casa. Medimos esse apoio a partir da proporção de votos coincidentes com aquele do líder do governo no Senado, já que não há registro sistematizado da orientação de lideranças na Casa. Na ausência de voto do líder, utilizamos o vice-líder como referência e, finalmente, o senador Flávio Bolsonaro, filho do presidente. 
Figura 8. Apoio ao governo em votações nominais no Senado (\%)

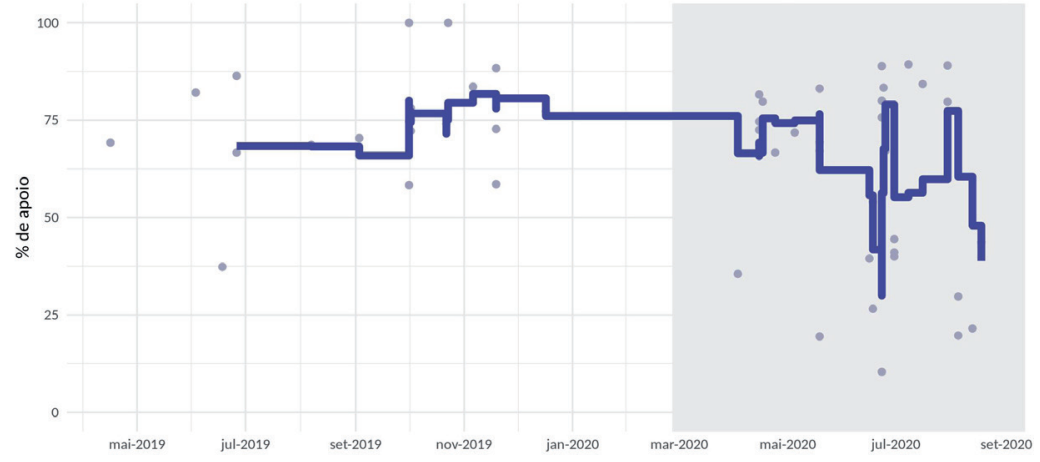

Fonte: Observatório do Legislativo Brasileiro (OLB).

Obs.: Pontos são votações, excluindo consensuais. Linha é a média móvel.

Até a pandemia, as médias de apoio ao governo se mostraram relativamente estáveis, em patamar seguro para aprovação de sua agenda (na casa dos 75\%). Durante a crise sanitária, no entanto, com a implantação do SDR, houve redução desse indicador (faixa dos 60\%). As taxas passaram a oscilar mais, com vários casos em que o Executivo não obteve apoio sequer da metade dos parlamentares votantes, o que denota uma mudança significativa com relação ao padrão anterior.

Tabela 13. Apoio médio ao governo em votações nominais no Senado (\%), antes e durante a pandemia

\begin{tabular}{ll}
\hline Período & Média \\
\hline Pré-pandemia & 74,7 \\
\hline Pandemia & 59,3 \\
\hline
\end{tabular}

Fonte: Observatório do Legislativo Brasileiro (OLB).

Para melhor avaliar o conflito entre Senado e governo durante a pandemia, analisamos mais detidamente o percentual de votações em que a taxa de apoio ao governo foi inferior a 50\%. Houve um salto muito significativo do indicador antes e durante a pandemia, de 4,5\% 
para $37,5 \%$, o que revela a fragilidade da posição política do governo na Casa e de sua capacidade de articulação no plenário. Em quase $40 \%$ das votações, a partir de março 2020, o governo foi minoritário.

Tabela 14. Votações nominais no Senado com apoio ao governo inferior a $50 \%$, antes e durante a pandemia

\begin{tabular}{lcc}
\hline Período & $\%$ & Número total de votaçóes \\
\hline Pré-pandemia & 4,5 & 22 \\
\hline Pandemia & 37,5 & 32 \\
\hline
\end{tabular}

Fonte: Observatório do Legislativo Brasileiro (OLB).

A última figura desta seção compara o apoio prestado ao governo pelos principais partidos da atual legislatura. Houve redução em praticamente todas as bancadas relevantes de centro-direita, inclusive nas que integram a base do governo, com maior variação média no DEM, partido do presidente da Casa. Apenas no PT houve algum crescimento no apoio médio ao governo, provavelmente em razão de seu patamar inicial muito baixo. $\mathrm{O}$ partido, ainda assim, continua a apresentar a menor taxa de governismo dentre as sete legendas observadas.

Figura 9. Apoio médio ao governo em votações nominais no Senado (\%), por partido

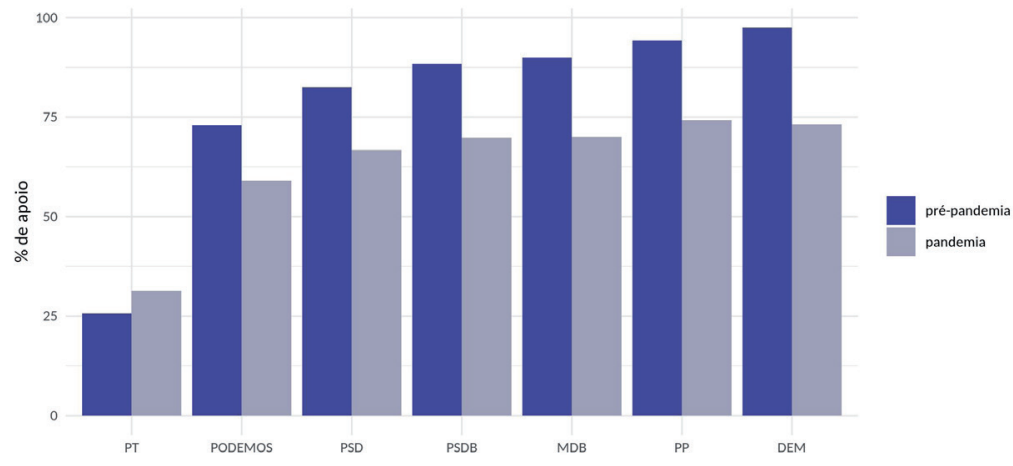

Fonte: Observatório do Legislativo Brasileiro (OLB). 


\section{Conclusões}

A pandemia de Covid-19 trouxe enormes desafios ao Congresso Nacional, que rapidamente deu respostas efetivas e de grande importância à sociedade, sem que os trabalhos das duas casas legislativas tenham sido descontinuados, ainda que a custo de inúmeras perdas sob o ponto de vista do controle e da participação social no processo legislativo. Quando comparado ao período anterior, o trabalho legislativo mudou em pontos sensíveis durante a pandemia.

No Senado, o quadro geral do período pode ser assim resumido: a) agenda majoritariamente relativa à pandemia, com foco em temas de saúde, num evidente deslocamento de esforços anteriormente dirigidos a proposições de menor relevância e impacto sociais; b) provável aumento do grau de acordo com a Câmara dos Deputados, na medida em que grande parte das votaçôes apreciadas pelos Senadores não retornou à Casa legislativa iniciadora; c) manutenção do grau de consenso entre os parlamentares em comparação ao período não pandêmico de atividades da legislatura; $\mathrm{e}$ d) redução expressiva da taxa de apoio ao governo após implantação do SDR, embora sem grandes mudanças na distribuição de partidos governistas e oposicionistas.

Assim, em que pese a instituição de um processo legislativo com déficits ainda maiores de participação e transparência, o que observamos como resultado não foi maior adesão ao governo, como era de se esperar no caso de o Legislativo apresentar um comportamento exclusivamente fisiológico. Na verdade, o afastamento do Senado em relação ao governo foi ainda mais expressivo do que o verificado na Câmara, onde também se verificou uma queda na taxa de apoio ao governo durante a pandemia.

Assim, a aproximação entre o governo e o "centrão", verificada no mesmo período, não resultou em adesão cega do Congresso à agenda do Planalto. Essa constatação é importante e revela uma dinâmica mais complexa da política brasileira do que a impressão de 
primeira vista. É preciso sublinhar, nesse sentido, que a decisão de Bolsonaro estruturar uma coalizão majoritária no Congresso veio apenas após sucessivas derrotas no Legislativo, já no segundo ano de governo. Ainda assim, uma costura sólida requer mais que apenas a distribuição de cargos na máquina pública, exigindo também habilidosa liderança política tanto no Planalto quanto nas casas legislativas.

Por fim, e principalmente, a pandemia abriu um conflito aberto entre presidentes e governadores, que assumiram posições opostas na coordenação da crise sanitária. Esse conflito, que também teve reflexo na Câmara, impacta sobremaneira o Senado, que tem por delegação justamente representar as unidades estaduais. Em outras palavras, mesmo em momento de funcionamento excepcional e de representação política prejudicada, o Senado mostrou-se muito sensível aos interesses dos estados, a ponto de adotar postura mais crítica que a da Câmara, em clara inversão do padrão observado no primeiro ano de mandato, quando os senadores propiciaram o governo com um mínimo de estabilidade face ao ânimo mais crítico e conflitivo de deputadas e deputados. Superada a pandemia, é possível que o Senado volte ao padrão comportamental anterior, desde que as ações do governo sejam menos danosas e contraditórias com o que preferem os entes federados. 